\title{
Speech Categories in the Context of the Movie A Separation
}

\author{
Faranak Nemani
}

Postgraduate Researcher, Islamic Azad University, Najafabad Branch Email: faranaknemani@yahoo.com

\section{Abbass Eslami Rasekh}

(Asso Prof. University of Isfahan). abbasseslamirasekh@yahoo.com

\section{Doi:10.5901/jesr.2013.v3n2p237}

\begin{abstract}
The study presented here was conducted to classify speech based on functional effects by using Searl's theory of pragmatic functions. The data of the study constituted the entire conversations among the main characters of the movie called A Separation. The procedures involved first, transcribing the conversations between the characters of the movie, next, the theory of pragmatics was applied in order to categorize the data and to examine how successfully our data could be classified based on the model. The findings revealed thatutterances could be classified functionally within a framework calledSearl's five major functional classifications (1976).It was further discovered that among the five major functions, two categories were rarely used in that specific context which incorporated mostly settings with conflict. The frequency order of the three most used categories was directive, expressive, and commisive respectively. The findings of the study could have implications for communicative language teaching programs, in the sense that those categories which occur most frequently require a greater proportion of the course content.
\end{abstract}

Key words:Speech Function, Seal’s Functional Theory, course content

\section{Introduction}

Functions of speech are unlimited; but, pragmatists have introduced classification types, According to Searl's theory of pragmatic functions (1976), speech functions can be classified into five major categories: Commissive, Declarative, Directive, Expressive, and Representative. Another theorydeals with functions in a different manner in the sense that the analyst is able to judge the function of the speech in a given context known as the illocution. In addition to the teaching of the grammatical structure of sentence and discourse which is part of the language teaching programs, the function of a given utterance, or a set of utterances making a pragmatic unit, needs to be studied and incorporated into the teaching content. Among the theories of functional analysis, functions could be either interactional, or transactional (Yule and Brown 1983); in addition, speech act theory (Brown \& Levinson, 1987) considers the illocution of the speech, the one intended by the speaker and detected by the addressee. Searl's classification has been the framework which was employed in order to analyze the movie data in this study. The five way classification of speech was verified through examining the speeches of the world introduced by six major characters of the movie A Separation. The data type has advantages to other non-natural types of data such as DCT types of questionnaires; the reason is that primarily nothing is lost from the analysts' awareness of the contexts of speeches within a world which is created. Thus, a fair degree of homogeneity is provided for considering speech produced in a spontaneous way. The social attributes of the characters represent the normal everyday life proceedings of a community which is stratified into different speech groups socially variable from one another.

The goal of applying the classification has been to verify the claims made about functions; furthermore, the findings could be useful in discovering how in certain contexts, some given speech categories are relatively more expected to occur which could have implications for students of language studies. 


\section{Literature review}

Research into Pragmatics has, for decades, considered the syntax to be the major component constituting the primary component of competence; and universals have been discovered showing how in the deep levels, languages are surface manifestations of a common deep underlying system. However, despite the role of universals in syntax, the approach to communicative aspect shows that universal pragmatic principles become culture specific to the extent that relativity emerges not only within differing groups of speakers of Persian, but also across typologically different languages. The universal principles become so culture specific that they could easily cause communication clashes. Linguists who have passed the stage of accepting syntax to be the native speakers' competence, turned their attention to the pragmatic aspects; they have often focused on speech act production in the context of use (Takahashi and Beebe, 1990; Blum-Kulka et al., 1989; Takahashi, 1996; and Matsumura, 2001). Requests, apologies, complaints, etc. have received a great deal of attention over the years. Some pragmatists considered a limited approach who analyzed, in most cases, the use of speech acts from a semantic-logical and cognitive viewpoint by describing the routines employed in realizing particular speech acts trying to identify the conventional implicatures in a rather logical style of analysis. In those cases, the analysis is placed on one (or two at best) single conversational turns isolated from their context; thus, providing a partial account of what actually takes place in communication.

As one of the basic tenets and phenomena of pragmatics, speech act theory hasbeen examined in many fields, including philosophy (Austin,1962; and Searle, 1976) anthropology, ethnography, sociolinguistics, and linguistics (Sadock, 1974; Bach \&Harnish,1979). While research differs on how speech acts are examined, the underlying theoryloosely remains the samewhen applied in appropriate situations. The common sense is that viewing speech in terms of acts which are actionsperformed through words. While typologies of speech acts differ across field and philosophy, the Searle'stypology will be the basis for this study because of the broad classification of speechtypes it introduces helping to uncover when, why, and how certain categories are frequent in contrast with a few which are of low frequency.

Searle developed five basic kinds of speech acts that we use toexpress the communicative intent and purpose in speaking: - representatives include basic assertions made by the speaker, which contain a truthvaluetestable in the propositional level. If someone says, I state that the earth is flat, anassertion has been made, although the statement is false.Directives are utterances made in an attempt by the speaker to get the hearer to dosomething for him. The directives may be expressed in different forms, such asin question form or in command form like Would you mind passing the salt? Or Pass the salt. In either case, the speaker wants the hearer to pass the salt and there are sociolinguistic explanations for each of the options. The third category is referred to as commissives; these actions commit the speaker to some future event or action. These also express what the speaker intends to do, such as promising, threatening, or swearing, e.g. I promise to be there in the morning. In using the commissives, the speaker is making an understood contract with the hearer thatwill be carried out. The fourth category incorporates the expressives which express psychological states of the speaker's mind andtell how the speaker feels. Examples of expressives are statements of happiness Joy! Joy! Joy! Thanking someone: Thanks, apologizing I'm sosorry, dislikes You bought me this?, and pain Mother of Christ! These, of course, must be context dependent because the illocutionary and perlocutionary forces may be interpreted differently in alternative environments. Whereas the locutionary act of expressives may be used for other categories.The final category includes - declaratives, which are statements made by the speaker's authority and cause immediateaction from the utterance. These are only effective when stated by the appropriate authority. For example I hereby pronounce you man and wife in turn officially causes the couple to be wed, and can take effect only if said by a priestor someone who carries authority to wed individuals. Within this system, Searle addressed possible intentions of speakers and desired actions of the utterances for different situations. Others have offered alternative classifications and different typologies to expand on or argue dissent with Searle (Hancher, 1979; Bach \& Harnish, 1979; Lyons, 1977). They argue that there are different levels of Speech Acts and that the classifications are not as easy to classify as suggested by Searle. Theyargue that it would be difficult to classify every utterance using the five classifications discussed above. However, while the classification has been challenged, the introduction of a functional model which could explain better the classifications is yet to be expected. 


\section{Method}

In order to classify speech based on functional effects through applying the functional theory of searl (1976), the main characters of the popular Iranian movie known as A Separation, were selected and their conversations in various contexts were recorded and transcribed. For classifying the utterances, as could be obvious, there is not necessarily a one to one correspondence between the syntactic units and the functional ones. The correspondence between the two aspects could not be predictable; while it is possible to have a one to one correspondence, this condition could never exist in most instances in which more than a unit of syntax made a given unit of function. Below, the measures taken to make the data comparable, the procedures, what we introduce as an instrument, etc will be discussed.

\section{Instrument}

In our common academic culture, an instrument is a means of collecting comparable data referring most often to questionaires which could be made in various styles with various goals giving us the generalizable norm to be discovered in the phenomena. In this study, we reason that the movie has been considered as an instrument providing us with the required data comparable and prototypical. We could have used other types of data. however, since the research question is to show which functional category is most common and which is least common, we did not employ measures for collecting homogeneous data assuming that a movie could provide data with a degree of homogeneity required for the study. As a novel and rare choice, we decided to limit the context to what has been demonstrated by the movie characters in differing settings; this has been the major reason why the Iranian movie called $A$ separation was used as the instrument to be employed for collecting data.The movie has gained popularity, won the Oscar prize, and is accessible to the analysts who wish to examine the validity of the findings. The world created by the movie was the context of situations with six main characters acting in various contextual situations.

\section{Procedures}

In order to examine the functional classification of speeches made by the movie characters through employing the speech act theory (Searl, 1976) we first listed the conversations while transcribing the data, classifying them into functional categories, we tried to identify the category, as carefully as possible to turn to data which was scattered into general lists of categories produced by each one of the six major characters who has topical salience in most of the conversations. Getting to an estimation of how frequent was each speech act category in the speeches of the six characters of the story; judgments were made through the help of a group of analysts, as it was turned into a controversial issue. The judgments with better reasons provided would be the one accepted. The issue for tackling was to decide if an utterance which represented a speech category could be the building block of a larger unit. Ultimately, the theory did not require dealing with the hierarchical structure of speech units; the utterance in single or paired, could give us a reason for considering the mixture to be a functional category achieved. To compare the differences between the characters in various contextual settings, the speeches of every character were transcribed with information available regarding where, when, in which circumstance (agreeing, conflicting, arguing, quarrelling, requesting etc) the speech was made. Having the categories ready and classified, comparisons were possible to be made between characters, across the two languages, and under the influence of contextual influences.

\section{Data Analysis}

This study needed two kinds of analysis: qualitative and quantitative: The data constituting speech was categorized based on different speech acts, the comparisons of which were shown by examples. As the quantitative analysis, the qualitative data were turned into quantitative by measuring frequency and percentage of every speech category produced by the characters in contextually different situations. The frequency of occurrence was used as criteria for comparison. Different Tables and Figures presented an illustration of comparisons from various perspectives; however, the most important perspective was for us to see under given 
circumstances which category of functions occurred most frequently. The use of excel as a computer statistical data base was a sufficient statistical tool for us to get to what is of interest to our research.

\section{Results: Functional Classification of the Utterances Based on Searl’s Theory (1976)}

There are possibly unlimited types of illocutionary acts and that is why, for better understanding and orientation, some linguists proposed their classification. The classification which is the most cited in the linguistic literature is that of Searle who divides illocutionary (speech) acts into five major categories:

Representatives are such utterances which commit the hearer to the truth of the expressed proposition (e.g. asserts, claims, reports). Example one is a display of a state which points out this category:

English 1: J to S: If her father doesn't give permission, she can't come with you, Ma'am.

TL: J to S: father-ash (3rd sing) if permission na- (neg) give ( $3^{\text {rd }}$ sing) ne- (neg) mi-(present) can (present)- eh ( $3^{\text {rd }}$ sing) with you ( plu) bi-( subjunc) come (present $3^{\text {rd }}$ sing) lady.

Persian 1: Pedare-sh age ejazenade ne-mi-toonanbashomabiyadkhanoom

$$
\text { قاضى بـ سيمين: بلدرث اكر اجازه نلده نميتون باشما بيادخانم }
$$

English 2: T to N: My teacher said so.

Persian 2: T to N: Khanoomgofte lady teacher tell ( $p p, 3^{\text {rd }}$ sing)

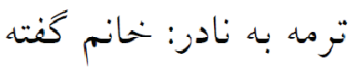

English 3: N to T: What is wrong is wrong. No matter who says or where it's written.

$T L$ : N to T: thing- I (indef) that wrong-eh (be $3^{\text {rd }}$ sing) wrong-eh (be $3^{\text {rd }}$ sing), every one mi- (pres mark) want ( $3^{\text {rd }}$ person sing) be- (subjun) say ( $3^{\text {rd }}$ sing) and everywhere also written become ( subjunc)- and ( $3^{\text {rd }}$ plur).

Persian 3: $N$ to T: chizikeghalateghalate, harkasi mi-khadbegevaharja ham neveshtebashand

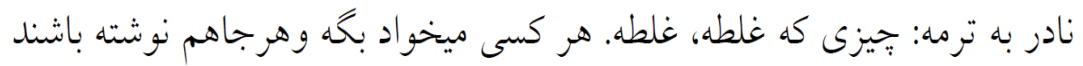

Directives are attempts by the speaker to get the addressee to do something (e.g. suggestions, ordering, requesting): Example four represents use of directives in the conversation in the court by the Judge to Nader who is accused of murdure:

English 4: J to N: You just sign here and get out. Call someone for the bail. (Direct request) Persian 4: In-o emzakon-id tashrif be-bar-id biroon. Zang be-zan-id vasighevasat-oon bi-yar-and This-o (om) signature do-( $2^{\text {nd }} \mathrm{pl}$ ) honor (formal respectful substitute for go) be- (subju) take (imp, present, $2^{\text {nd }} p l$.

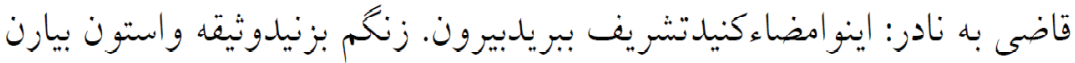

English 5: $R$ to S: No please. I beg you not to take these words outside here. (Direct request with using mitigation device

TL5. $R$ to S: no, you (sing) ro (OM) Quoran. I swear-to you ( $p l)$ mi-(present) give-am ( $1^{\text {st }}$ sing) this speech-ha (pl marker) from this-place out na-(neg marker) go (subju mood).

Persian 5: $R$ to S: Na to roghoran. Man ghasam-e-toon mi-de-am in harfhaaz in jabiroonnare

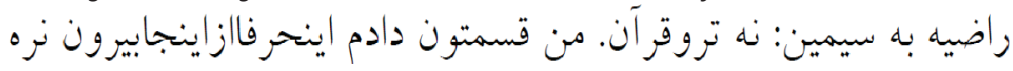

C. Commissives commit the speaker to some future course of action (e.g. promise, offer, threat). A group of speech acts with this nature constitute this category. Example six shows a unit which uses first an order and a conditional threat. Both together make a request direct and impositive demonstrating the power practiced by the speaker:

English 6: J to $\mathrm{H}$ : be quiet or I'll send you to jail for three days. (Threat)

TL: I to H: silent become- in (2nd plursubjunct) and unless mi- (present mark) send -am ( first sing) - toon (

$2^{\text {nd }}$ plu) for 3 day detention be-( subjunc)- shi (present)- in ( $2^{\text {nd }}$ plural).

Persian 6: J to H: Saket bash-in vaela mi-frestam-e-toonbaraye se roozbazdasht be-sh-in 


$$
\text { قاضى بـ حجت: ساكت بانشين و الى ميفرستمتئن برايى سه روزز بازداشت بشين }
$$

Example seven shows how an indirect threat is made and is classified in the commissives. Then a threat is intensified by another threat showing the nature of language in intensifying the function is supposed to convey.

English7: $H$ to S: Ma'am, I have nothing to lose in life. Tell your husband to not do something that'll get both us in big trouble.

LT: H to S: lady, I think-I (indefinite) na- (neg) have (present) am ( $1^{\text {st }}$ sing) in life- im (first sing, possessive adj) be- (subjunc) lose (present)-am ( $1^{\text {st }}$ sing). to husband-et ( possessive $2^{\text {nd }}$ sing) be- (subjun) say (present) one work-I (indefin) na-( neg) do-e ( $3^{\text {rd }}$ sing) I crazy become (subjun $1^{\text {st }}$ sing) also self-am ( $1^{\text {st }}$ sing)-o (obj marker) unluky mi-( present $m$ ) do- (preset)- am ( $1^{\text {st }}$ sing) also he-ro (obj $m$ ).

Persian 7: $H$ to S: Khanoom man chizinadaram too zendegim be-bazam. Be shohar-et begooye karinakon-e man divoon-e sham ham khod-am-o bad bakht mi-kon-am, ham oon-o

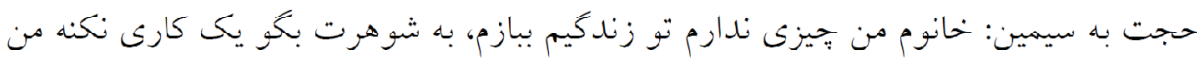

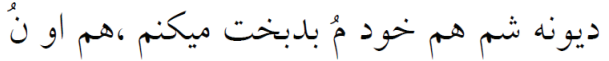

D. Expressives express a psychological state (e.g. apologies, complains, thanks) expressed in terms of a view point or an indirect different function. Mentioning indirectly a complaint in the form of an expressive by Termeh to her mother is intended to be guilt to be placed on the addressee indirectly; however, direct speech is formed in terms of a conditional: jailing the father was the cause of leaving of the mother. The speaker is revealing the information to show her feelings about that: anger as a result of leaving the father. This way of arguing could be more complicated; however, we have to suffice by saying that this unit is an instance of expressive speech. Within this frame work speech in question is expressive, as the speaker is expressing her feeling by complaining, while in the framework of speech act, it is a unit of criticism.

English8: T to S: If you hadn't left, Dad wouldn't have been in jail now. (Complaint)

LT: $T$ to S: you if now leave (present) na- (neg) done (past pariciple) be (past)-I ( $2^{\text {nd }}$ sing) be-( subj) go ( present)- $i\left(2^{\text {nd }}\right.$ sing) dad now in jail na-( neg) be (past $3^{\text {rd }}$ sing).

Persian 8: $T$ to $S$ : to age alanvelnakard-e bood-i beri baba alan to zendanna-bood.

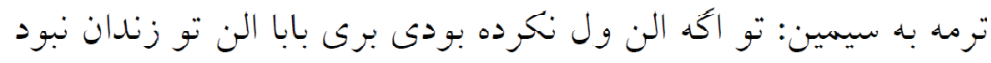

Extract nine shows how an expressive is used for the purpose of defense. She is trying to place the blame on the father to satisfy the daughter she was not responsible for jailing the father. The daughter placed the blame, the mother in 9 replaced the blame on the father reasoning that he hit the pregnant woman. The majority of the professional analysts agreed with us that the entire unit is to convey feelings while in speech act we call them indirect rejection of criticism (defense) in which reason speech act has been used to form a speech unit called disagreement or defense.

English 9: $S$ to T: Your father isn't in jail because of me. He hit a pregnant lady.

LT: S to T: dad- $t$ (2nd sing) with favor I in jail ni-(neg) be (present $3^{\text {rd }}$ sing), one woman- e (of) pregnant ro ( obj $m$ ) beating hit( past $3^{\text {rd }}$ sing).

Persian 9: $S$ to T: Babat be khatere man too zendannist ye zan e bardarrokotakzade.

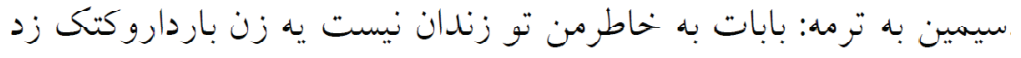

English 10: S to T: Cause you left, this women came here. (Complaint)

$T L$ : you leave (past non honorofic $\left.V, 2^{\text {nd }} \operatorname{sing}\right)$ do-I $\left(2^{\text {nd }}\right.$ sing past) go (past)- $i\left(2^{\text {nd }}\right.$ sing) that this lady come (past 3td sing) here.

Persian 10: S to T: To velKardirafti in khanoomoomadinja.

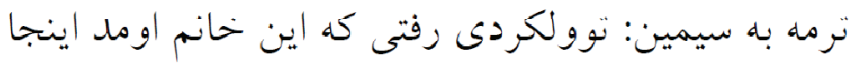

Extract 10 is another instance of expressive speech, while in the framework of speech act it is an indirect complaint. It is interesting to notice how the speaker's attitude realized in complaining in a critical style could affect her tone of speech. She uses singular $2^{\text {nd }}$ person, and for expressing you left, she uses a substitute that exists in Persian used only to criticized (velkard- $\mathrm{i}=$ free do-I $\left(2^{\text {nd }}\right.$ sing) 
Example 11 is the suitable case of expressive with the expressive function. It is an instance of interactional use of speech, meant to thank or to show gratitude:

English 11:S to MsGhahrayi: I'm sorry for your trouble. (Apology)

LT: S to MsGhahrayi: very you fall- in ( $2^{\text {nd }}$ plu) to trouble be-(subj $m$ ) forgive (present)- id ( $\left.2^{\text {nd }} p l u\right)$.

Persian 11: S to MsGhahrayi: kheilishomaoftadid be zahmat be-bakhsh-id.

11 does not get a semantic translation; as it is praise in Persian, while it is judged to be apology in English version. We can see how numerous functions may change in the process of translation.

$$
\text { .'.سيمين به خانم قهر ايى: خيلى شما افتادين به زحمت ببخشيد.'. }
$$

E. Declarations effect immediate changes in the institutional state of affairs (e.g. .christening, declaring war). The category which was not found in our data was this one. This functional category has been named as performatives which do not carry any illocution. The declarations could be different in our framework in contrast with speech act of Austin represented by Brown and Levinson (1987). A lot could be mentioned in this respect, but for saving space, additional points of difference will be ignored left for another study.

The speech acts made by all the characters were classified into four out of five categories of speech acts based on the Searl(1976): Commisive (42), Directive(98), Expressive(59), and Representative (3) .Figure 4.18 shows the percentage of the speech acts in each four categories as mentioned before. The highest percentage of the speech acts were directive (46\%) as we naturally expect it to be since the contexts dominant throughout the movie involve confrontations.And $29 \%$ of the speech acts were expressive which constituted the second category in rank, $21 \%$ were commisives which incorporated the third category in rank. The lowest percentage of the speech acts (1\%) was representatives and in the world of $A$ Separation, there were no instances of declarative. The most frequent speech category was directive and the least frequent was the representative with $3 \%$ and declaratives which made up zero percent of the categories of functions.

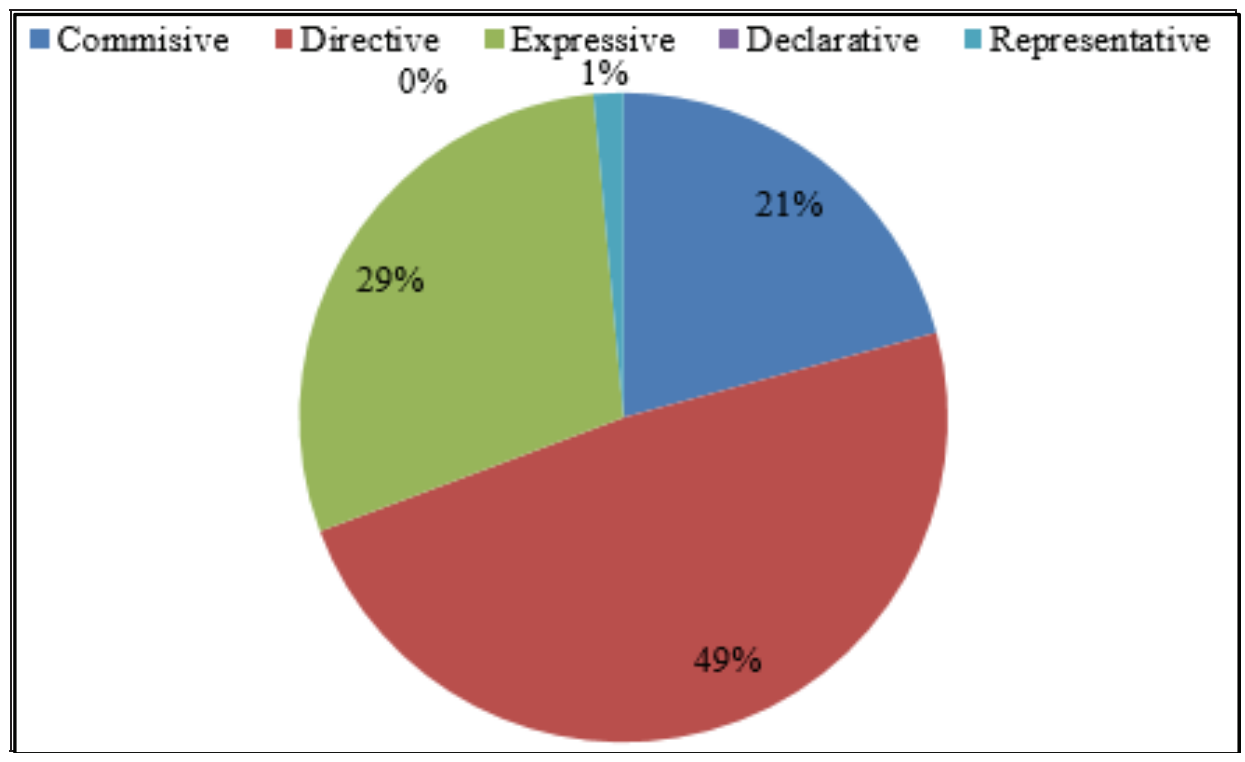

Figure 4.18. The Percentage of the Speech Acts of AllCharacters in Searle's Categories

Table 4.4 shows the frequency of the speech acts as uttered by the main characters, (Nader, Simin, Termeh, Hojat, and the Judge). The five-way classification was used in order to divide the data into the categories mentioned. In this way, we can examine how frequently use is categories of speech in entire collection of the speech acts (Searl, 1976). The highest frequency of the speech acts was directives (72). 45 tokens of speech acts were expressive, which was the second category in rank .37 tokens of speech acts were 
commisive which was the third category in rank. And finally the lowest frequency of the speech act (3) included representatives. And the last category named as declaratives was not found in the data examined for the study.

Table 4.4. The Frequency of the Speech Actsof the Main Characters in Each Searl's Functional Category

\begin{tabular}{|l|l|l|l|l|l|}
\hline $\begin{array}{l}\text { Searl's Categories } \\
\text { of the speech acts }\end{array}$ & Commisive & Directive & Expressive & Declarative & Representative \\
\hline Speech acts & 37 & 72 & 45 & 0 & 3 \\
\hline
\end{tabular}

Figure 4.19 shows the percentage of the speech acts of the main characters in each category of the speech acts regardless of which character said what to whom in a given context. The highest percentage of the speech acts were directives (51\%). $27 \%$ of the speech acts were expressive which was the second category in rank and $20 \%$ of the categories were commisives which included the third category in rank and the lowest percentage of the speech acts (2\%) were representatives; and the last category of speech which is called declaratives was not found in the data of the study.

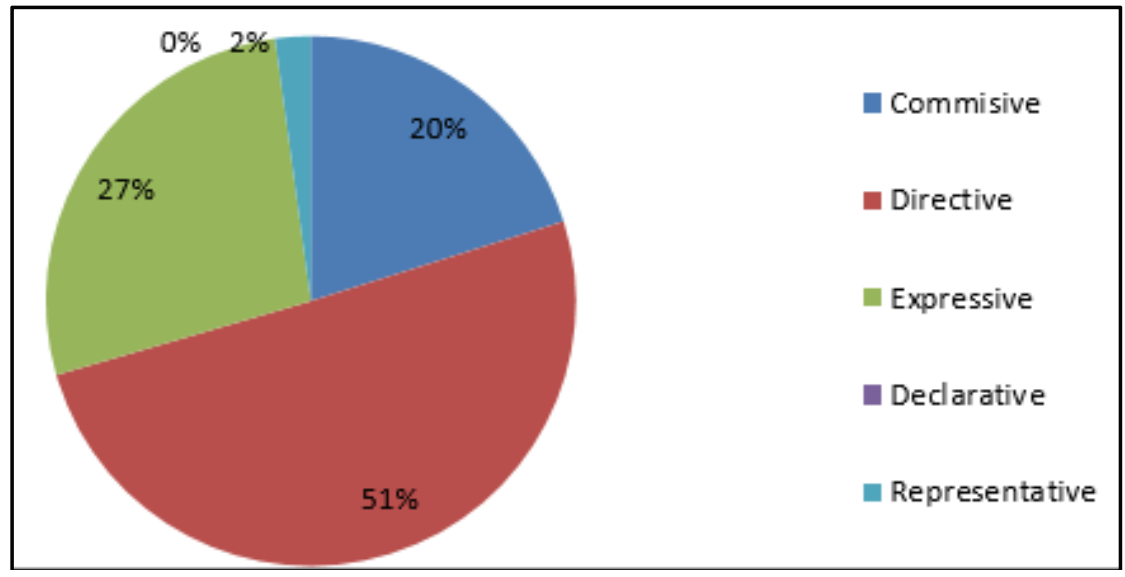

Figure 4.19. The Percentage of the speech acts of the Main Characters in Each Searl's Functional Category

The bars on Figure 4.20show the frequency of the speech categories in four out of five groups introduced by Searl (1976). The comparison is done to discover which speech category is of most vital need and hence is most frequently used regardless of other contextual elements: commisive, directive, expressive, and representative. The highest frequency of Nader's functional speech category (28) belongs to directives 18 instances were Expressive, which was the second category in rank; 14instances were commisive which was the third category in rank. and the lowest frequency of Nader's speech function (1) was representative. In contrast, The highest frequency of Simin's speech functions (11) included directives. Next, expressives with the frequency of 7 and commisives with the frequency of 6 instances which occurred in our data were the second category in rank. As for Raziye's speech functions, the ranking was 13 tokens were directives. Commisives with the frequency of 4 constituted the next, and expressives with the frequency of 3 were the subsequent categories in rank. In the case of Hojat's speech functions in comparison with others, the highest frequency of speech functions was (9) instances of Expressive. 7 speech functions were directive, the second category in rank; and finally the lowest ranking of functions in Hojat's speech was (2) representatives. Concerning Termeh, The highest frequency of functions is: (8) were expressive; 2 for commisive and 2 for directive the second category in rank. The highest frequency of The judge's speech functions included (11) directives. 9 commisives were the second category in rank and finally the lowest frequency was (2) for representatives. 


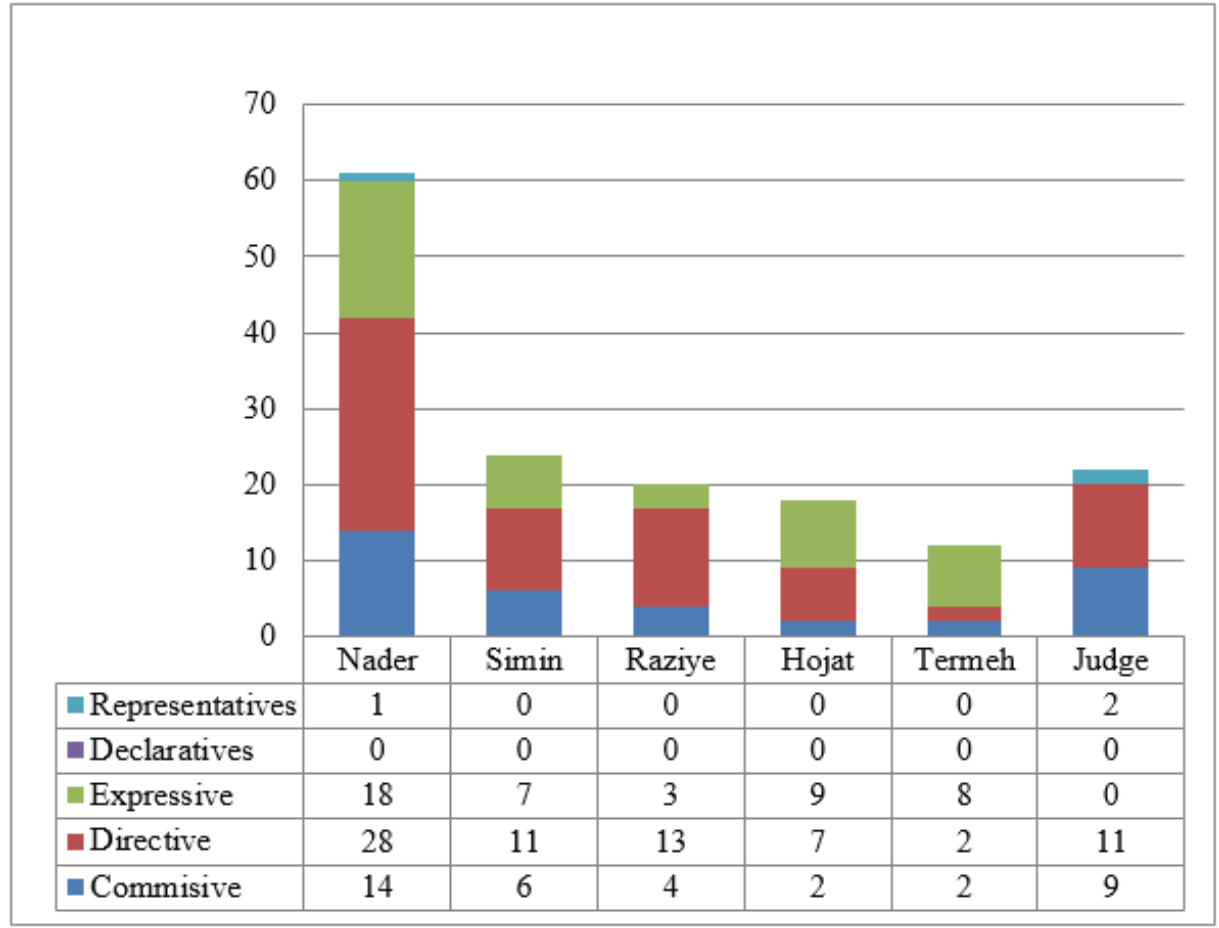

Figure 4.20. The Frequency of the Speech Acts of Each Main Character in Each Searl'sCategory

Figure 4.21 shows the percentage of the speech acts of Nader in each category of the speech acts. The highest percentage of his speech acts was directive (60\%). $26 \%$ of his speech functions were expressive forming the second category in rank and $12 \%$ of his speech were commisives which was the third category in rank and the lowest percentage of Nader's speech functions (2\%) was representative.

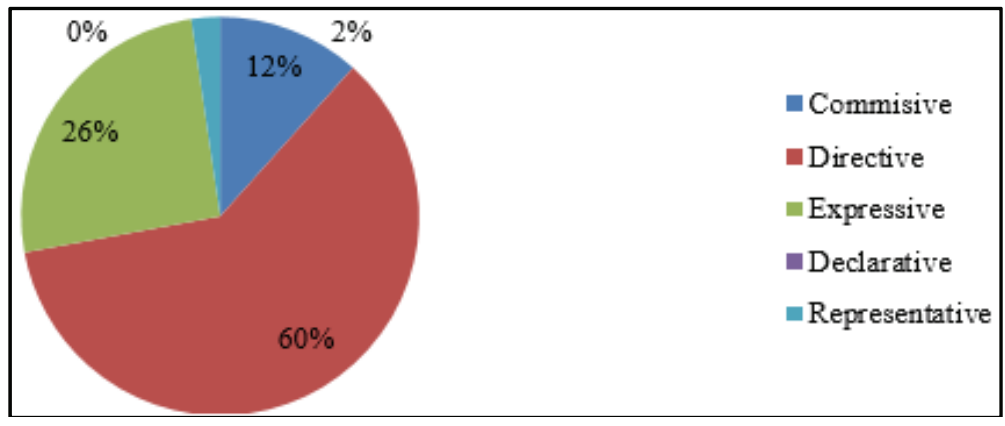

Figure 4.21. The Percentage of the Speech Acts of Nader in Searl's Functional Categories

Figure 4.22 shows the percentage of the speech acts of Simin in each category of the speech acts. The highest percentage of her speech functions was directives (46\%). The next was $29 \%$ of her speech acts which were expressives, the second category in rank and $25 \%$ of her speech function were commisives which was the third category in rank. 


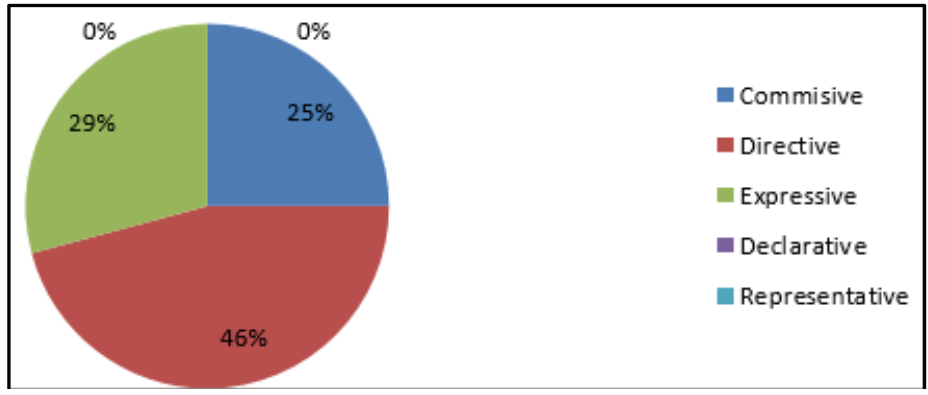

Figure 4.22.The Percentage of the Speech Acts of Simin in Searl's Functional Categories

Figure 4.23 shows the percentage of the speech functions which were identified in Hojat's speeches in each category of the speech acts. The highest percentage of his speech functional categories were expresives (50\%). 39\% of his speech acts were directives which was the second category in rank. and the lowest percentage of his speech acts were commisives (11\%).

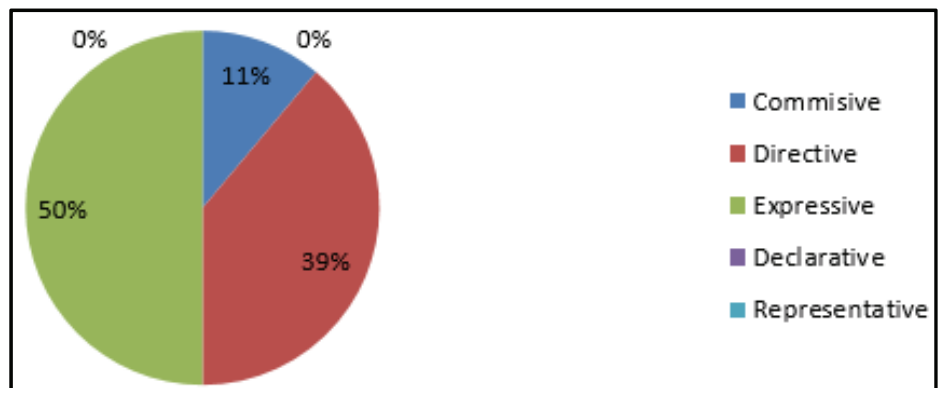

Figure 4.23.The Percentage of the Speech Acts of Hojat in Searl's Functional Categories

Figure 4.24 shows the percentage of the functional categories identified in the speeches made by Raziyeas divided into the five-way categories of the speech functions. The highest percentage of her speech were directives (65\%). $20 \%$ of her speech were commisives making the second category in rank. and the lowest percentage in Raziye's speech were expressives (15/.).

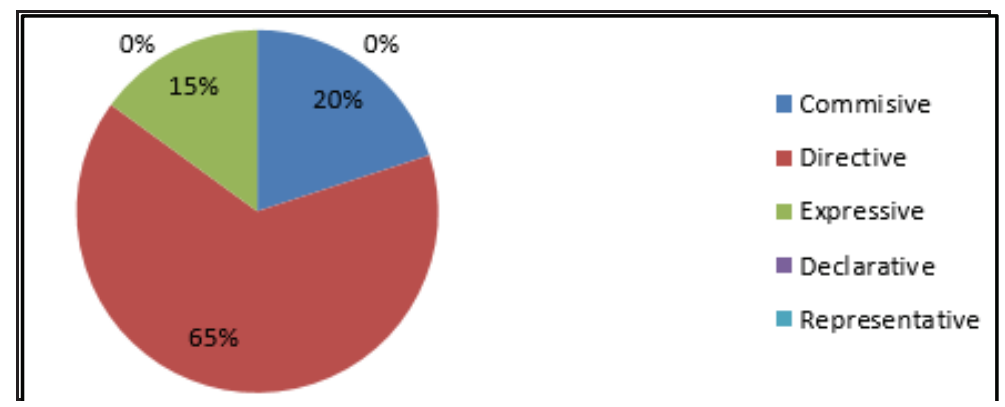

Figure 4.24. The Percentage of the Speech Acts of Raziye in Searl's Functional Categories

Figure 4.25 shows the percentage of the speech acts classified in terms of functions made by Termeh in each category of the speech acts. The highest percentage of her speech category were expressive (67\%). $17 \%$ of 
her speech acts were directives which was the second category in rank and16\% of her speech acts were commisives which was the third category in rank.

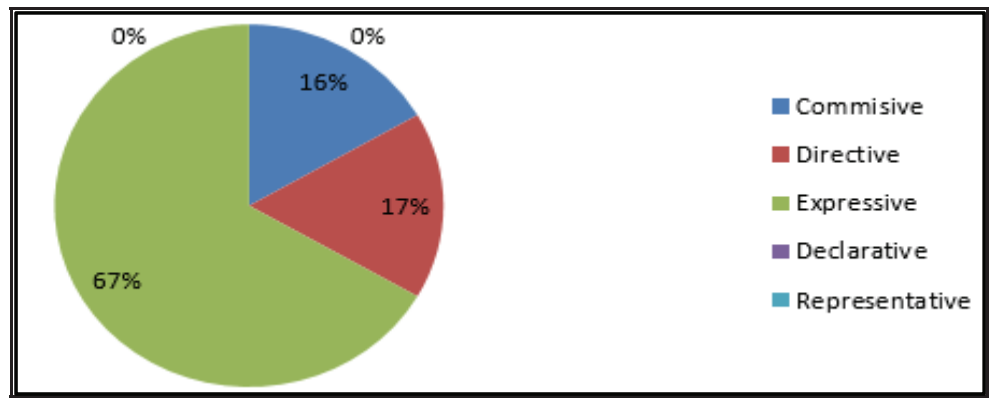

Figure 4.25. The Percentage of the Speech Acts of Termeh in Searl's Functional Categories

Figure 4.26 shows the percentage of the speech acts of the Judge in each category of the speech acts. The highest percentage of his speech acts were directives (50\%). $41 \%$ of his speech acts were commisives which was the second category in rank; and the lowest percentage of the Judge's speech acts (9\%) were representatives.

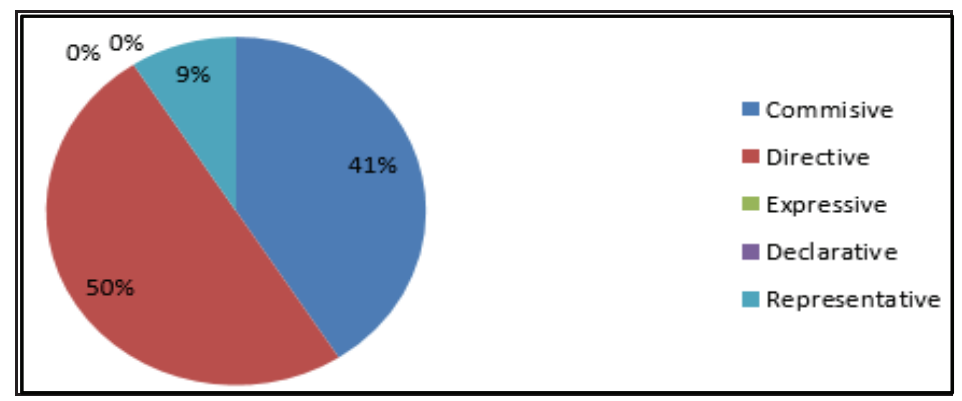

Figure 4.26. The Percentage of the Speech Acts of The Judge in Searl`s Functional Categories

In table 4.6, the speech acts of the main characters were classified into Seal's five categories of the speech acts and their frequency of occurrence was measured based on an estimation of which characters uttered them to which addressees (Nader, Simin, Raziye, Hojat, Termeh, the Judge). Directive speech acts (26) as the highest most frequently used speech acts in Nader's utterances, mostly were said to Raziye(12). Nader also said (7) directive speech acts toTermeh and (5) to Hojat and (2) to Simin and the Judge. Expresive speech acts (18) were the second frequently used speech act in Nader's Utterances which were said mostly to Simin (7) and Raziye (6) respectively. Nader also said (2) expressive speech acts to Termeh and the Judge and (1) to Hojat. Commisive speech acts (14) as the third category in the rank were mostly said to Simin (9).Nader also uttered (3) commisive speech acts to Raziye and (1) to Hojat and Termeh. Representative speech (1) as the lowest frequently used speech function was uttered once by Nader to Termeh.

Directive speech acts (11) as the highest frequently used speech acts in Simin's utterances, were mostly said to Nader (5). Simin also said (3) directive speech units to Termeh and (1) to each of Hojat, Raziye, and the judge. Expresive speech acts (7) were the second frequently used speech acts in Simin 'sutterances which were said mostly to Nader (6) and just one to Raziye. Commisive speech acts (6) as the third category in the rank were mostly said to Nader (3). Simin also said (2) commisive speech acts to Termeh and (1) to Hojat.

Directive speech acts formed (13) the highest frequently used speech units in Raziye`s speech, mostly said to Nader (6). Raziye also said (4) directive speech acts to the Judge, (2) to Simin and (1) to Hojat. Commisive speech acts (4) were the second frequently used speech functions in Raziye's speech which were said to only 
Nader (4). Expresive speech acts (3) as the third category in the rank were said to Nader (2) and Simin (1).

Expressive speech acts (9) as the highest frequently used speech acts were identified in Hojat's utterances, mostly said to Nader (8) and (1) to Raziye. Directive speech acts (7) were the second frequently used speech act in Hojat'sutterances which were said mostly to Nader (3). Hojat also said (2) directive speech units to each one of Raziye and the Judge. Commisive speech acts (1) as the third category in the rank were said to Simin (1).

Expressive speech acts (8) as the highest frequently used speech acts in Termeh's utterances were said to Nader (4) and Simin (4). Directives and commisives were identified in Termeh's speech to N and Swith the same frequency (2), the Second category in the rank. Directives (11) as the highest frequently used speech units in the Judge's utterances were said to Simin (6) and Nader (5). Commisive speech units (9) were the second frequently used speech function in the Judge's utterances which were directed mostly to Hojat (7). The Judge also said (3) commisive speech acts to Nader and (1) to Termeh. Representative speech acts (2) as the least frequently used speech function in the Judge's utterances was said to Simin.

Table 4.5. Classification of the Speech Acts of the Main Characters into Searl's Categories of the Speech Acts Regarding Who is addressing Whom

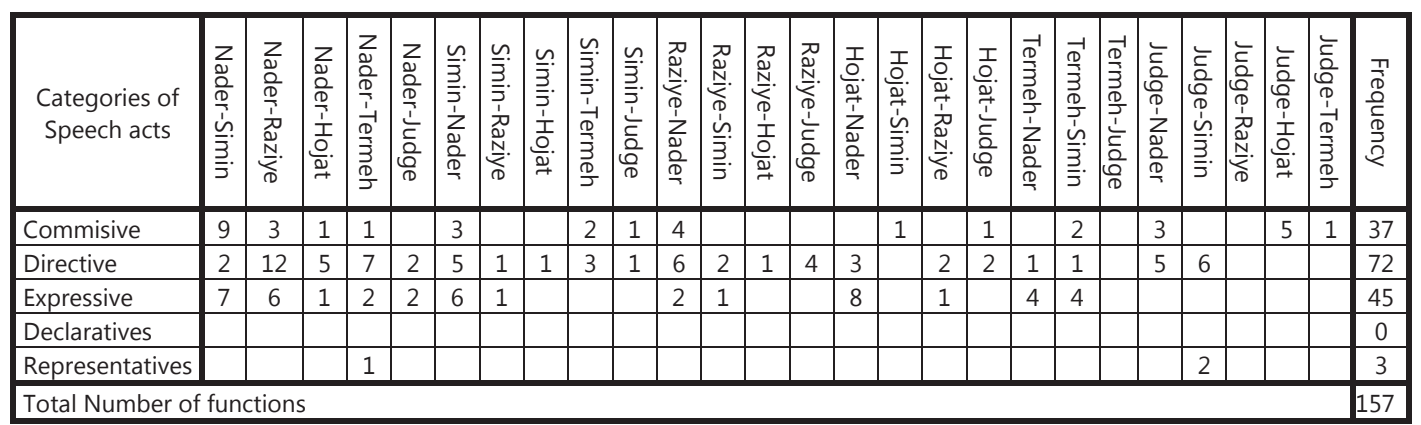

Bars in Figure 4.27 show the frequency of the speech acts in each one of searl's categories of speech functions. Comparing the frequency of speech functions across different characters was intended to uncover if the situation of the character has anything to do with the types of speech one makes. The frequency of occurrence was measured and compared in terms of bar-Figures based on an estimation of which characters uttered which speech function and to which addressees (Nader, Simin, Raziye, Hojat, Termeh, and the Judge).

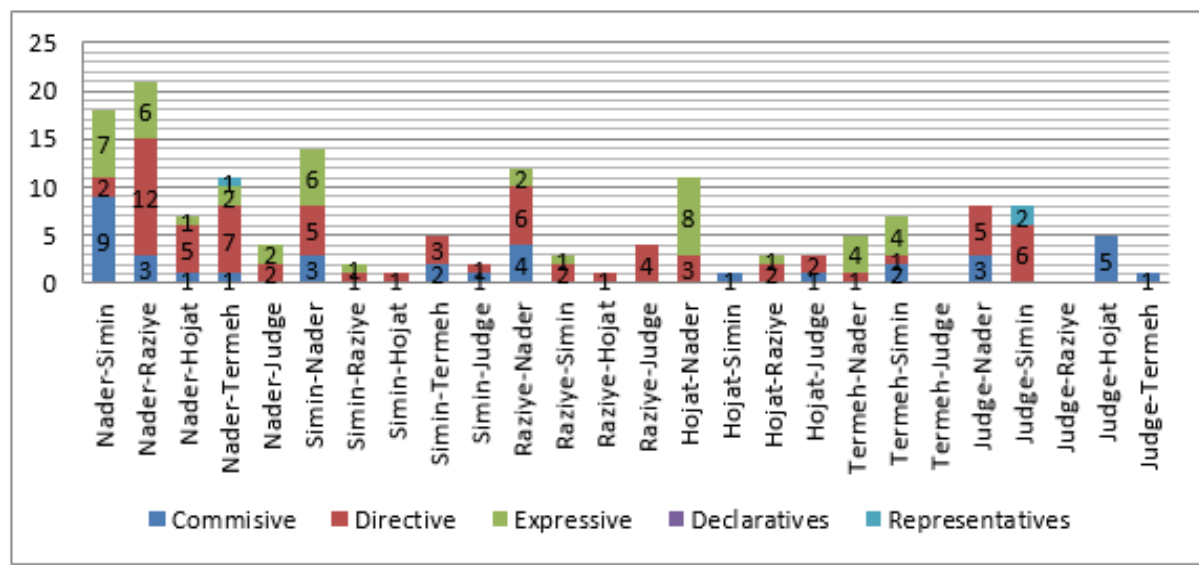

Figure 4.27. The Classification of the Speech Acts of the Main Characters into Searl'sFunctional Categories Regarding Who is Addressing Whom 
The new finding was that certain functions are highly frequent while others might be rare in speech. The five-way classification of Searl was applied and our examination showed that one function was rare among the functions mentioned in the theory.

\section{Summary and Conclusion.}

The study presented in this article aimed to verify the claims made by Searl. It was decided to employ a movie as an instrument of providing data; this is a novel approach as the goal is to apply the Searl's model. The data included conversations of six major characters of the movie. The assumption is that speech is multi-functional; on the other hand, speakers live in a multi-dimensional space being surrounded by such factors as age, status, quality of relations, and class. The qualitative analysis was presented which showed how in close examinations, the role of the muliti-dimentional space is observed in the speeches of various characters under various contextual circumstances. The next section of the study was the quantitative comparisons which were presented in tables and figures. The classificational criteria could be troublesome as it was not an easy task to issue an opinion in a defendable way. Complications would inevitably be part of changing the qualitative data to the quantitative data; but in approximational terms, we could say that the classifications of the conversations were in agreement with what we assumed to be expected from the contexts of confrontations. The last point was the rarity of declarative which requires a specific especial data to occur, and representative speech was rare as the contexts of the movie did not assumably ask for it. The findings of this study are useful for communicatively oriented language teaching courses which emphasize for the use of language being appropriate is more vital than being structurally right. Serious discourses could lead to mis-communication; and English is learnt not for the sake of its grammar, but for real serious communicative purposes.

\section{Reference}

Austin, J. (1962). How to do things with words. Oxford: Clarendon Press.

Bach, K. and R. Harnish. (1979). Linguistic communication and speech acts. Cambridge: MIT Press.

Blum-Kulka, Sh, House, J.,\& Kasper, G. (1989). Cross-Cultural Pragmatics: Requests and apologies. Norwood: Ablex Publishing. Linguistic, pp. 305-322.

Hancher, M. (1979). The classification of co-operative illocutionary acts. Language in society, pp 8, 1, 1-14.

Lyons, J. (1977). Semantics, Vols. 1\& 2. Cambridge: Cambridge University Press.

Matsumura, S.h. (2001). Learning the Rules for Offering Advice: A quantitative Approach to Second Language Socialization.Language Learning 51(4), pp. 635-679.

Searle, J. (1976). A classification of illocutionary acts. Language in Society, pp. 5(1), 1-23.

Sadock, J. (1974). Toward a linguistic theory of speech acts. New York: Academic Press.

Takahashi, S. (1996).Pragmatic Transferability.Studies in Second Language Acquisition, pp. 18.

Takahashi, S., \& Beebe, L. (1990).Pragmatic Transfer in ESL Refusals, in R. Scarcella, S. Krashen and E, Anderson (Eds). Developing Communicative Competence in a Second Language (55-73). Cambridge, MA: Newbury House. 